\title{
Intestinal parasites and genotyping of Giardia duodenalis in children: first report of genotype $B$ in isolates from human clinical samples in Mexico
}

\author{
Julio César Torres-Romero' ${ }^{1 /}$, Antonio de Jesus Euan-Canto ${ }^{1}$, Namibya Benito-González ${ }^{1}$, \\ Nayely Padilla-Montaño², Claribel Huchin-Chan'1, Julio Lara-Riegos ${ }^{1}$, Roberto Cedillo-Rivera ${ }^{3}$ \\ 'Laboratorio de Análisis Clínicos de Servicio a la Comunidad 'Laboratorio de Farmacología, Facultad de Química, \\ Universidad Autónoma de Yucatán, Mérida, Yucatán, México ${ }^{3}$ Unidad de Investigación Médica Yucatán, \\ Unidad Médica de Alta Especialidad, Instituto Mexicano del Seguro Social, Mérida, Yucatán, México
}

Giardia duodenalis is one of the most prevalent enteroparasites in children. This parasite produces several clinical manifestations. The aim of this study was to determine the prevalence of genotypes of $\mathrm{G}$. duodenalis causing infection in a region of southeastern Mexico. G. duodenalis cysts were isolated (33/429) from stool samples of children and molecular genotyping was performed by polymerase chain reaction-restriction fragment length polymorphism (PCR-RFLP) analysis, targeting the triosephosphate isomerase (tpi) and glutamate dehydrogenase (gdh) genes. The tpi gene was amplified in all of the cyst samples, either for assemblage A (27 samples) or assemblage B (6 samples). RFLP analysis classified the 27 tpi-A amplicons in assemblage A, subgenotype I. Samples classified as assemblage $B$ were further analysed using PCR-RFLP of the gdh gene and identified as assemblage B, subgenotype III. To our knowledge, this is the first report of assemblage B of $\mathrm{G}$. duodenalis in human clinical samples from Mexico.

Key words: Giardia duodenalis - genotyping - PCR-RFLP - tpi - gdh - enteroparasites

Giardia duodenalis (syn. Giardia lamblia, Giardia intestinalis) is one of the most common intestinal parasites of humans and is the cause of giardiasis (Adam 2001). A variety of molecular studies, including polymerase chain reaction-restriction fragment length polymorphism (PCR-RFLP) and sequence analysis of the glutamate dehydrogenase $(g d h)$, triosephosphate isomerase (tpi), efla, bg and 18S RNA genes, have shown that $G$. duodenalis can be classified genetically in distinct genotypes or assemblages (Monis et al. 2003). Assemblages $\mathrm{A}$ and $\mathrm{B}$ can infect humans and other mammals, which support zoonotic transmission. Assemblage A is divided into two subgenotypes, I and II, and assemblage B into subgenotypes, III and IV. Assemblages $\mathrm{C}-\mathrm{H}$ have been reported only in domestic and wild animals (Monis et al. 2003, Lasek- Nesselquist et al. 2010).

In Mexico, the reported prevalence of giardiasis varies from $3-50 \%$ in different regions of the country. Children one-10 years of age have a particularly high prevalence in the states of the southeast region (CedilloRivera et al. 2009). Despite the high prevalence of giardiasis, molecular epidemiology studies of Giardia in Mexico are still scarce. Previous studies performed in Mexico with human isolates have reported only the pres-

doi: 10.1590/0074-0276140507

Financial support: UADY/PIFI

+ Corresponding author: julio.torres@uady.mx

Received 21 October 2013

Accepted 10 January 2014 ence of assemblage A (sub-assemblages A-I and A-II) (Ponce-Macotela et al. 2002, Cedillo-Rivera et al. 2003, Eligio-García et al. 2005, 2008a, b, Lalle et al. 2005). However, these studies were all performed with samples from the central and north of Mexico. No previous studies have been conducted with samples from the southeast of the country. The aim of this work was to genotype $G$. duodenalis in children from Merida, located in southeast of Mexico, to provide additional information on the molecular epidemiology of this parasite in the country.

This study was conducted in Merida and was approved by the Ethical Committee of the Regional Research Centre Dr Hideyo Noguchi of the Autonomous University of Yucatán (UADY) (protocol CEI-CIR-UADY-201215). Single stool samples were taken from 429 subjects of both genders, aged one-14 years and referred to the Clinical Analysis Laboratory of Community Services of the Faculty of Chemistry, UADY, between January 2012-June 2013. All of the stool samples positive for $G$. duodenalis were processed for DNA extraction, which was performed using the QIAamp DNA Stool Mini Kit (Qiagen, Germany) according to the instructions of the manufacturer, with a minor modification: the incubation time for proteinase $\mathrm{K}$ treatment was extended overnight. DNA samples were stored at $-20^{\circ} \mathrm{C}$ until further use.

Two separate PCR reactions with specific primers (TPIAIF-TPIAR) to amplify a 476-bp fragment for assemblage $A$ and specific primers (TPIBIF-TPIBR) to amplify a 140-bp fragment for assemblage B were performed as previously reported by Amar et al. (2002). A third set of primers were used for the amplification of the $g d h$ gene as a single PCR, with specific primers (GDHiFGDHiR) to amplify a 432-bp fragment, as described by Read et al. (2004). Positive and negative controls were 
also included in each PCR to validate results. PCR was performed on a thermal cycler (C-1000 Bio-Rad) and the final products were visualised on silver-stained $6 \%$ nondenaturing polyacrylamide gel (29:1).

For PCR-RFLP analysis, the tpi and $g d h$ PCR products were digested with $5 \mathrm{U}$ of the endonuclease $R s a \mathrm{I}$ (New England Biolabs) in a final volume of $30 \mu \mathrm{L}$ for 3 $\mathrm{h}$ at $37^{\circ} \mathrm{C}$. The $R s a \mathrm{I}$ digestion allowed discrimination between sub-assemblages A-I and A-II from the tpi-A amplicons and discrimination between sub-assemblage BIII and sub-assemblage B-IV from the $g d h$ amplicons.

Intestinal parasite infection was detected in 84 out of $429(19.6 \%)$ samples analysed. The subjects comprised 41 males (48.8\%) and 43 females (51.2\%), with a median age of five years and ranging from one-14 years old. Protozoa were the most prevalent parasites detected in these children (92.8\%). Blastocystis hominis was the most common intestinal parasite $(53.6 \%)$, followed by $G$. duodenalis (39.3\%). All parasites identified are shown in Table. Most of the children were infected with one parasite $(72.6 \%)$, followed by the patients with two parasites $(16.7 \%)$, with three parasites $(7.1 \%)$ and with four parasites $(3.6 \%)$. The most frequent cases of multiple parasitic infections were $G$. duodenalis, B. hominis and Endolimax nana. There were no significant gender differences. This finding is in agreement with previous results of other intestinal parasite surveys from various population groups in Mexico (Quihui-Cota \& MoralesFigueroa 2012). Giardia is one of the major diarrhoeal agents in humans. It is distributed worldwide and the infection has a major clinical impact on children that are five years old or younger (Adam 2001). Of the 84 samples with enteric parasites, 33 were positive for $G$. duodenalis (39.3\%). The highest prevalence of G. duodenalis infection (21.2\%) was found in five-year-old children, followed by three and four-year-olds, with a prevalence of $9.1 \%$ each. These findings reflect that $G$. duodenalis is the most frequent pathogenic enteroparasite in the population of children studied.

\section{TABLE}

Intestinal parasites detected in stool samples from children of Merida, Mexico

\begin{tabular}{lc}
\hline Parasite & $\begin{array}{c}\text { Infected children } \\
(\mathrm{n}=84) \\
\mathrm{n}(\%)\end{array}$ \\
\hline Blastocystis hominis & $45(53.6)$ \\
Giardia duodenalis & $33(39.3)$ \\
Endolimax nana & $30(35.7)$ \\
Entamoeba coli & $4(4.8)$ \\
Trichuris trichiura & $2(2.4)$ \\
Enterobius vermicularis & $2(2.4)$ \\
Hymenolepis nana & $1(1.2)$ \\
Chilomastix mesnilli & $1(1.2)$ \\
Ascaris lumbricoides & $1(1.2)$ \\
\hline
\end{tabular}

Genotyping is increasingly being applied in the surveillance of $G$. duodenalis transmission. The tpi gene was successfully amplified in all samples (as 2 single amplification reactions for assemblages A and B). Of these samples, 27 (81.8\%) amplified for assemblage A using the primers TPIAIF-TPIAR. The PCR products of these 27 samples were digested with $R s a \mathrm{I}$, with all generating a band of $437 \mathrm{bp}$, which corresponds to subgenotype A-I (Fig. 1). With the primers TPIBIF-TPIBR, six samples (18.2\%) amplified as assemblage B. To determine the B subgenotypes of these samples, an amplification using the specific primers GDHiF and GDHiR for the gdh locus was performed and the expected band of $432 \mathrm{bp}$ was observed. The PCR product was digested with RsaI, generating two bands of $130 \mathrm{bp}$ and $300 \mathrm{bp}$, indicating that the six iso-

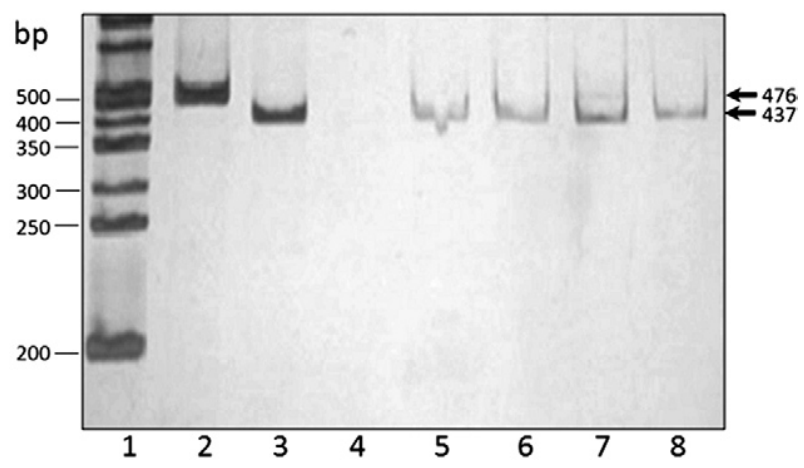

Fig. 1: identification of subgenotypes A by polymerase chain reaction (PCR) amplification based on the triosephosphate isomerase (tpi) gene. Lane 1: molecular size standards; 2, 3: positive control (Giardia duodenalis subgenotype A-I); 4: negative control; 5-8: Giardia isolates. Silver stained polyacrylamide gel shows in the Lane 2: the amplicon of the PCR (476-bp) based on tpi gene of G. duodenalis for assemblages A; 3, 5-8: DNA pattern of restriction fragment length polymorphism analysis (437-bp) after digestion with RsaI corresponding to the subgenotype A-I.

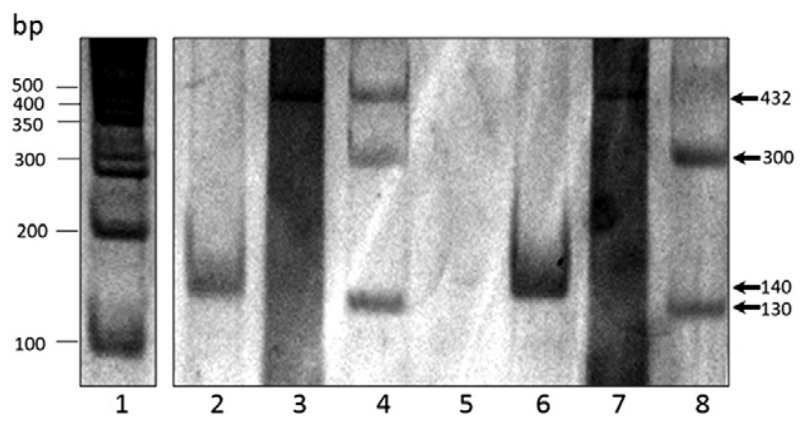

Fig. 2: identification of subgenotypes B by polymerase chain reaction (PCR) amplification based on the triosephosphate isomerase (tpi) and glutamate dehydrogenase $(g d h)$ genes. Lane 1: molecular size standards; 2, 6: amplicons of the PCR (140-bp) based on tpi gene of Giardia duodenalis for assemblage B; 3, 7: amplicons of the PCR (432-bp) based on $g d h$ gene of $G$. duodenalis; 4, 8: DNA pattern of restriction fragment length polymorphism analysis (300-bp and 130-bp) after digestion with $R s a$ I corresponding to the subgenotype B-III; 5: negative control. 
lates belong to subgenotype B-III (Fig. 2). Several studies have been performed in Mexico regarding genotypes of G. duodenalis in samples obtained from humans. PonceMacotela et al. (2002) reported an unusual $100 \%$ prevalence of the Giardia A-II subtype in isolates from humans in Mexico City. Cedillo-Rivera et al. (2003) reported that the Giardia A-I subtype is ubiquitous in Mexico City. Lalle et al. (2005) reported that all isolates tested belonged to genotype A. Eligio-García et al. $(2008 \mathrm{a}, \mathrm{b})$ reported the presence of genotypes A-I, A-II and a mixture of both from samples of clinical isolates. From these studies, 110 isolates from humans belonged to genotype A (64 from axenic isolates and 46 from stool samples) and none to genotype $\mathrm{B}$, an unusual result considering that genotype $\mathrm{B}$ has been reported in most series of cases worldwide. Moreover, genotype B has been reported in several studies as the most frequent genotype (Molina et al. 2011, Ignatius et al. 2012, Atherton et al. 2013).

Differentiation between genotypes A and B is important because they differ in virulence. Genotype A is usually related to intermittent diarrhoea, whereas genotype B is related to complaints of persistent diarrhoea (Homan \& Mank 2001). However, it was difficult to compare our results with the findings of other investigations due to the lack of clinical data on the children. Interestingly, however, only the individuals with genotype B showed watery stools with mucus, in contrast to the other individuals (data not shown). In summary, we report the first information about the distribution of the two major genotypes of G. duodenalis in southeast Mexico and the first cases of a Giardia-genotype B infection in Mexican children.

\section{ACKNOWLEDGEMENTS}

To Dr José Manuel Hernández Hernández, for the DNA controls gifted, and to the clinical-chemist Giovanni Xool Castellanos, for technical assistance.

\section{REFERENCES}

Adam RD 2001. Biology of Giardia lamblia. Clin Microbiol Rev 14: 447-475.

Amar FL, Dear PH, Pedraza-Díaz S, Looker N, Linnane E, McLauchlin 2002. Sensitive PCR-restriction fragment length polymorphism assay for detection and genotyping of Giardia duodenalis in human feces. J Clin Microbiol 40: 446-452.

Atherton R, Bhavnani D, Calvopiña M, Vicuña Y, Cevallos W, Eisenberg J 2013. Molecular identification of Giardia duodenalis in Ecuador by polymerase chain reaction-restriction fragment length polymorphism. Mem Inst Oswaldo Cruz 108: 512-515.

Cedillo-Rivera R, Darby JM, Enciso-Moreno JA, Ortega-Pierres G, Ey PL 2003. Genetic homogeneity of axenic isolates of Giardia intestinalis derived from acute and chronically infected individuals in Mexico. Parasitol Res 90: 119-123.

Cedillo-Rivera R, Leal YA, Yépez-Mulia L, Gómez-Delgado A, Ortega-Pierres G, Tapia-Conyer R, Muñoz O 2009. Seroepidemiology of giardiasis in Mexico. Am J Trop Med Hyg 80: 6-10.

Eligio-García L, Cortes-Campos A, Cota-Guajardo S, Gaxiola S, Jiménez-Cardoso E 2008a. Frequency of Giardia intestinalis assemblages isolated from dogs and humans in a community from Culiacan, Sinaloa, Mexico using beta-giardin restriction gene. Vet Parasitol 156: 205-209.

Eligio-García L, Cortes-Campos A, Jiménez-Cardoso E 2005. Genotype of Giardia intestinalis isolates from children and dogs and its relationship to host origin. Parasitol Res 97: 1-6.

Eligio-García L, Cortes-Campos A, Jiménez-Cardoso E 2008b. Classification of Giardia intestinalis isolates by multiple polymerase chain reaction (multiplex). Parasitol Res 103: 797-800.

Homan W, Mank T 2001. Human giardiasis: genotype linked differences in clinical symptomatology. Int J Parasitol 31: 822-826.

Ignatius R, Gahutu JB, Klotz C, Steininger C, Shyirambere C, Lyng M, Musemakweri A, Aebischer T, Martus P, Harms G, Mockenhaupt FP 2012. High prevalence of Giardia duodenalis assemblage B infection and association with underweight in Rwandan children. PLoS Negl Trop Dis 6: e1677.

Lalle M, Jimenez-Cardosa E, Cacciò SM, Pozio E 2005. Genotyping of Giardia duodenalis from humans and dogs from Mexico using a beta-giardin nested polymerase chain reaction assay. $J$ Parasitol 91: 203-205.

Lasek-Nesselquist E, Welch DM, Sogin ML 2010. The identification of a new Giardia duodenalis assemblage in marine vertebrates and a preliminary analysis of $G$. duodenalis population biology in marine systems. Int J Parasitol 40: 1063-1074.

Molina N, Minvielle M, Grenóvero S, Salomón C, Basualdo J 2011. High prevalences of infection with Giardia intestinalis genotype $\mathrm{B}$ among children in urban and rural areas of Argentina. Ann Trop Med Parasitol 105: 299-309.

Monis PT, Andrews RH, Mayrhofer G, Ey PL 2003. Genetic diversity within the morphological species Giardia intestinalis and its relationship to host origin. Infect Genet Evol 3: 29-38.

Ponce-Macotela M, Martínez-Gordillo MN, Bermúdez-Cruz RM, Salazar-Schettino PM, Ortega-Pierres G, Ey PL 2002. Unusual prevalence of the Giardia intestinalis A-II subtype amongst isolates from humans and domestic animals in Mexico. Int J Parasitol 32: 1201-1202.

Quihui-Cota L, Morales-Figueroa GG 2012. Persistence of intestinal parasitic infections during the national deworming campaign in schoolchildren of northwestern Mexico: a cross-sectional study. Ann Gastroenterol 25: 57-60.

Read CM, Monis PT, Thompson RC 2004. Discrimination of all genotypes of Giardia duodenalis at the glutamate dehydrogenase locus using PCR-RFLP. Infect Genet Evol 4: 125-130. 